\title{
Determination of Vitamins A, C and D Status Using Serum Markers and a 24-Hour Dietary Recall among Maasai Women of Reproductive Age
}

\author{
Haikael Martin 1*, Pammla Petrucka², Joram Buza1 \\ ${ }^{1}$ Nelson Mandela African Institution of Science and Technology, Arusha, Tanzania \\ ${ }^{2}$ College of Nursing, University of Saskatchewan, Saskatoon, Canada \\ Email: ${ }^{*}$ martinh@nm-aist.ac.tz
}

Received 20 August 2014; revised 4 October 2014; accepted 5 November 2014

Copyright (C) 2014 by authors and OALib.

This work is licensed under the Creative Commons Attribution International License (CC BY). http://creativecommons.org/licenses/by/4.0/

(c) (i) Open Access

\section{Abstract}

We previously reported that the prevalence of oral thrush among Maasai women of reproductive age in Ngorongoro Conservation Area was abnormally high (32\%) in the absence of immune-compromising diseases such as HIV. This study was undertaken to test the hypothesis that Maasai women of reproductive age are prone to oral thrush because they are deficient in micronutrients such as Vitamins A, C, D, and B12, as well as iron and folate which are known to have immune modulating functions. Method: The study recruited 210 participants out of which 180 agreed to donate blood for serum separation and analyses. A total of 107 participants (including 28 with oral thrush and 79 without oral thrush) were assessed for dietary intake of iron, folate, Vitamins A, $C$, and B12 using a 24 hours dietary recall method. Further, 40 serum samples randomly selected from the 180 serum samples were tested for concentrations of Vitamins $A$ and $C$ using commercially available HPLC kit while the concentration of Vitamin D was tested using the commercially available 25-OH Vitamin D ELISA Assay kit. Statistical analysis was performed using IBM SPSS Statistics $20^{\mathrm{TM}}$, where descriptive and inferential statistics were applied to demographic, socioeconomic and biochemical variables. Student's t-test was used to test for significant differences among variables at $95 \%$ confidence level. The proportion of women with deficiency was calculated for single and multiple micronutrients. Results: Results from the 24-hour dietary recall method revealed that with the exception of folate $(p=0.000)$, there were no significant differences in iron, Vitamins A, C, and B12 intake between participants with and without oral thrush. Of note, the intake of these four micronutrients was below the Recommended Nutrient Intake (RNI). A similar trend was observed for serum vitamin concentrations as established by HPLC and ELISA testing. While there was no significant difference in serum concentration of Vitamins $A, C$, and $D$ between participants with and without oral thrush $(p>0.05)$, the serum levels were all below normal sig-

\footnotetext{
${ }^{*}$ Corresponding author.
}

How to cite this paper: Martin, H., Petrucka, P. and Buza, J. (2014) Determination of Vitamins A, C and D Status Using Serum Markers and a 24-Hour Dietary Recall among Maasai Women of Reproductive Age. Open Access Library Journal, 1: e893. http://dx.doi.org/10.4236/oalib.1100893 
nifying deficiency of micronutrients in the sample. Conclusion: Overall, this study revealed micronutrient deficiency in the women of reproductive age in the Ngorongoro Conservation Area, which may contribute to the previously reported high levels of oral thrush. Recommendations: Nutrition education directed to this community on the importance of eating micronutrient rich foods such as fruits and vegetables is highly recommended.

\title{
Keywords
}

Maasai Women, Micronutrients, Vitamins A, B12, C, D, Oral thrush, Ngorongoro Conservation Area

\author{
Subject Areas: Global Health, Nutrition, Women's Health
}

\section{Introduction}

Micronutrient deficiency is a public health concern in many parts of the world but more evident in developing countries [1]. Of particular public health importance are Vitamin A, iodine, and iron. Moreover, several micronutrients (i.e., Vitamins A, B12, C, folate, riboflavin, selenium and zinc) have immune-modulating functions thus influencing susceptibility of the host to infectious diseases, the course of such diseases, and clinical outcomes [2]. Micronutrients are nutrients required by humans in small quantities to coordinate a range of physiological functions. Micronutrients include dietary minerals such as zinc, selenium, sodium, iodine and vitamins like the B-complex group, Vitamins A, C, D, E and K. These nutrients variably enable the body to produce enzymes, hormones, and other substances essential for proper growth and development. Though required in small amounts, the consequences of their deficiency and/or absence are potentially severe and threaten the health and development of populations [2]. The prevalence of oral thrush among Maasai women of reproductive age living in Ngorongoro Conservation Area was reported to be 32\% [3]. This prevalence exceeded previous studies in immune-compromised populations which reported prevalence of 25\% [4] and 23.5\% [5] among HIV infected persons in Zambia and Tanzania respectively. In this study breastfeeding Maasai women had higher odds of getting oral thrush compared to the non-breastfeeding women [3]. This is supported by research findings which reported that lactating women have a relatively greater need for micronutrients and are more prone to the consequences of their deficiency [6]-[8].

Micronutrient deficiencies affect maternal newborn and child health. A pregnant woman may exhaust, deteriorate, and even die during childbirth due to such conditions. The consequences for the fetus and/or neonate may range from small for gestational age to physical or developmental challenges, and even miscarriage or neonatal death. A lactating woman's micronutrient status contributes to the health and development of her breastfed child especially in the first 6 months of life. For a young child, micronutrient deficiencies may lead to impairment of physical and cognitive development as well as an increased propensity for infectious diseases [9]. In resourcepoor communities, malnutrition is exclusively attributable not only to insufficient food quantities, but also to poor nutritional quality of available foods [10]. Micronutrient deficiencies impact on morbidity and mortality of a population and therefore need to be addressed adequately and urgently [11].

Micronutrients and infectious diseases normally coexist, exhibiting a complex interaction leading to a vicious cycle of malnutrition and infection especially in impoverished settings partly because of uniformly low consumption of foods rich in multiple micronutrients [1] [2]. In this study, we sought to determine the status of selected micronutrients including Vitamins A, B12, C, and D as well as iron and folate in relation to oral thrush occurrence amongst select Maasai women of reproductive age in Ngorongoro Conservation Area (NCA).

\section{Materials and Methods}

\subsection{Study Area}

The study was conducted in the NCA which is located west of Arusha Municipal in the C rater Highlands area of Tanzania. Ngorongoro District has a population of 174,278 of which males are 82,610 and females 91,668 with 46,750 of these being women of reproductive age [12]. The majorities of the population in this district are 
of Maasai origin and live in rural areas as pastoralists with primary dependence on cattle for their livelihoods [13].

\subsection{Study Design and Population}

The study was a cross sectional exploratory study as part of a larger initiative titled "Mama Kwanza (Mother First) Socio-economic/Health Initiative (MKSHI)" which is undertaking an integrated, inter-sectoral approach to maternal, infant and child health continuum in Arusha Region, Tanzania. The present study considered the micronutrient levels of selected women of reproductive age (15 - 49 years). Data was collected in November 2013 involving targeted Maasai women living in one of three villages in the NCA; namely, Olbalbal, Alelilai and Misigiyo.

\section{Sampling}

Systematic random sampling technique was employed in selecting serum samples to be analyzed. Due to budget constraints, a total of 40 serum samples were analyzed for Vitamin A, C and D. The sampling took to account the inclusion of serum samples from both the participants with and without oral thrush. The number of samples analyzed was 14, 13 and 13 in Olbalbal, Misigiyo, and Alelilai respectively. In all villages depending on the number of participants, the $\mathrm{n}^{\text {th }}$ sample was taken for analysis. Using the 24-hour dietary recall method, 107 subjects were assessed for dietary intake of Vitamin A, C, B12, folate and iron.

Data collection

1) Serum samples

Blood samples were taken using a 5-mm syringe into a vacutainer tube containing no anticoagulant. The blood was allowed to clot for 30 minutes. Serum was obtained by centrifuging (Eppendorf Centrifuge 5417R, Germany) the whole blood at 13,000 g for 15 minutes. Serum was separated from clot by pipetting the supernatant into vials which were then stored in a jar containing liquid nitrogen (Source: NAIC, Arusha). Upon arrival from the field, samples were stored at $-80^{\circ} \mathrm{C}$ until analyzed.

2) 24-hour dietary recall

One hundred and seven women were requested to provide information on food consumed over the previous 24 hours preceding the survey date. This technique sought to reveal the daily typical meal pattern and therefore market days and holidays were not included. Of the studied subjects, 28 were positive for oral thrush and 79 were negative. This method was used to estimate daily intake of Vitamin A, C, B12, folate and iron.

\section{Laboratory analysis}

Serum Vitamin A was determined using the High Performance Liquid Chromatography, HPLC System ${ }^{\mathrm{TM}}$ from Shimadzu, (Duisburg, Germany) procedure using a commercially available kit (Vitamin A and Vitamin E HPLC Assay ${ }^{\mathrm{TM}}$, Eagle Biosciences, USA). Serum Vitamin C was determined using a commercial kit Vitamin C HPLC Assay ${ }^{\mathrm{TM}}$ and Serum 25-hydroxyVitamin D was determined using a 25-OH Vitamin D ELISA Assay kit $^{\mathrm{TM}}$ (Eagle Biosciences, USA).

\section{Data analysis}

Descriptive statistics were applied to demographic, socioeconomic, and biochemical variables using descriptive and inferential statistics. Student's t-test was used to test for significant differences among variables at 95\% confidence level. The proportion of women with deficiency was calculated for single and multiple micronutrients. The results were expressed as mean $\pm S D$, with a p value of $<0.05$ considered significant. Statistical analysis was performed using IBM SPSS Statistics $20^{\mathrm{TM}}$.

\section{Ethics}

Ethical approval was sought and obtained from the National Institute for Medical Research (NIMR) Tanzania, certificate number NIMR/HQ/R.8a/Vol._IX/1474. Permission to conduct the study was also sought from Tanzania Wildlife Research Institute (TAWIRI) and also received from respective villages/wards governments. All study participants gave a written informed consent.

\section{Results}

\section{Demographics}

The women studied were more likely to be married, with the majority being illiterate (Table 1). A total of 210 women of reproductive age were involved in the study out of which 180 contributed blood samples. From these blood samples, 40 samples were randomly selected and analyzed for Vitamin A, C, and D. 
Table 1. Participants’ Demographic characteristics, vitamin and haemoglobin status.

\begin{tabular}{cc}
\hline Descriptive & Overall \\
Number of women & 210 \\
Age (years) & \\
Mean \pm SD & $27.6 \pm 7.3$ \\
Married & $89 \%$ \\
Education & \\
Illiterate & $68 \%$ \\
Primary & $28 \%$ \\
Secondary & $4 \%$ \\
Vitamin status & \\
Vitamin A $<1.24 \mu \mathrm{mol} / \mathrm{L}$ & $100 \%$ \\
Vitamin C $<11.4 \mu \mathrm{mol} / \mathrm{L}$ & $100 \%$ \\
$25-$ OH Vitamin D $\leq 75 \mathrm{nmol} / \mathrm{L}$ & $16 \%$ \\
Haemoglobin status & \\
Anaemic & $29 \%$ \\
Non anaemic & $69 \%$ \\
Were not measured (Refused) & $2 \%$ \\
\hline
\end{tabular}

\section{Estimation of daily nutrient intake of Vitamins A, B12, and C, Folate and Iron}

The results of 24 hour dietary recall of 107 study participants are presented in Table 2. Mean dietary intake of Vitamin A, B12, and C, iron and folate were $72.5 \mu \mathrm{g} \mathrm{RE} / \mathrm{d}, 0.8 \mu \mathrm{g} / \mathrm{d}, 2.9 \mathrm{mg} / \mathrm{d}, 9.7 \mathrm{mg} / \mathrm{d}$ and $318.6 \mu \mathrm{g} / \mathrm{d}$ respectively. The results revealed that there was no significant difference in Vitamin A, B12, and C, or iron intake among participants regardless of oral thrush status $(\mathrm{p}>0.05)$. However, folate levels were significantly different when the two groups (i.e., oral thrush present/absent) were compared $(\mathrm{p}=0.000)$.

\section{Serum Vitamin Analyses}

Serum levels of Vitamin A and C were below normal reflecting a deficiency of these two Vitamins. With regard to Vitamin D, about $16 \%$ of women had insufficient levels of serum 25-OH Vitamin D. An independent samples t-test was computed to compare serum levels of Vitamins A, C, and D in women with and without oral thrush. There was no significant difference in mean serum levels of Vitamin A, C, and D ( $>0.05)$ in these groups. Results for serum concentrations of Vitamins A, C, and D are summarized in Table 3.

\section{Discussion}

A high prevalence of Vitamins A and C deficiency (100\%) was observed in a sample of women of reproductive age living in villages around the Ngorongoro Crater regardless of their oral thrush status. The Tanzania Demographic and Health Survey (TDHS) [14] suggested that less than $1.24 \mu \mathrm{mol} / \mathrm{L}$ denotes Vitamin A deficiency, although there are other suggested levels [15] this national indicator was used in this study. Results obtained showed Vitamin A levels to range between 0.01 and $0.14 \mu \mathrm{mol} / \mathrm{L}$ among the studied women. With Vitamin D deficient there is no consensus as to the most appropriate cutoffs to define insufficiency. Some studies assert that the minimum levels to maintain a good health is $>50 \mathrm{nmol} / \mathrm{L}$ [16]; $>75 \mathrm{nmol} / \mathrm{L}$ [17]; and $\geq 100 \mathrm{nmol} / \mathrm{L} \mathrm{[18]}$. However, in this study, greater than $50 \mathrm{nmol} / \mathrm{L}$ of serum Vitamin $\mathrm{D}$ was taken to be sufficient to maintain good health, aligning with a prior study involving women of reproductive age [16]. Simultaneous deficiencies of Vitamin A, C, and D were examined. In the THDS [14], simultaneous deficiencies of more than two micronutrients were reported in more than $80 \%$ of the studied population. In this study, all serum samples analyzed were showed deficiency in Vitamin A and C and about 16\% showed a deficiency in Vitamin D. 
Table 2. Estimated dietary intake of Vitamin A, C, B12, Iron, \& Folate.

\begin{tabular}{|c|c|c|c|c|}
\hline Variable & Condition & Mean \pm SD & p-value & RNI \\
\hline \multirow[t]{2}{*}{ Vitamin A } & Oral thrush & $57.8 \pm 209.1$ & 0.599 & \multirow{2}{*}{500 - $850 \mu \mathrm{g} \mathrm{RE} / \mathrm{d}$} \\
\hline & No oral thrush & $77.7 \pm 165.2$ & & \\
\hline \multirow[t]{2}{*}{ Vitamin C } & Oral thrush & $2.1 \pm 3.6$ & 0.248 & \multirow{2}{*}{$70 \mathrm{mg} / \mathrm{d}$} \\
\hline & No oral thrush & $3.2 \pm 5.9$ & & \\
\hline \multirow{2}{*}{ Vitamin B12 } & Oral thrush & $0.8 \pm 4.2$ & 0.690 & \multirow{2}{*}{$2.8 \mu \mathrm{g} / \mathrm{d}$} \\
\hline & No oral thrush & $0.8 \pm 3.8$ & & \\
\hline \multirow[t]{2}{*}{ Iron } & Oral thrush & $10.2 \pm 8.3$ & 0.994 & \multirow{2}{*}{$\begin{array}{c}10-30 \mathrm{mg} / \mathrm{d} \\
\text { (bioavailability dependent) }\end{array}$} \\
\hline & No oral thrush & $9.5 \pm 8.4$ & & \\
\hline \multirow[b]{2}{*}{ Folate } & Oral thrush & $462.6 \pm 438.8$ & 0.000 & \multirow[b]{2}{*}{$500 \mu \mathrm{g} / \mathrm{d}$} \\
\hline & No oral thrush & $267.5 \pm 249.4$ & & \\
\hline
\end{tabular}

Table 3. Serum levels of Vitamin A, C and D.

\begin{tabular}{|c|c|c|c|c|}
\hline Variable & Condition & Mean \pm SD & p-value & Normal levels \\
\hline \multirow[b]{2}{*}{ Vitamin A } & Oral thrush & $0.09 \pm 0.03$ & 0.627 & \multirow[b]{2}{*}{$>1.24 \mu \mathrm{mol} / \mathrm{L}$} \\
\hline & No oral thrush & $0.082 \pm 0.03$ & & \\
\hline \multirow{2}{*}{ Vitamin C } & Oral thrush & $1.10 \pm 1.40$ & 0.991 & \multirow{2}{*}{$>11.4 \mu \mathrm{mol} / \mathrm{L}$} \\
\hline & No oral thrush & $1.13 \pm 1.03$ & & \\
\hline \multirow{2}{*}{ Vitamin D } & Oral thrush & $128.46 \pm 60.24$ & 0.575 & \multirow{2}{*}{$>50 \mathrm{nmol} / \mathrm{L}$} \\
\hline & No oral thrush & $135.71 \pm 59.36$ & & \\
\hline
\end{tabular}

To further explore the reason(s) that Maasai women of reproductive age are deficient in Vitamins A and C, dietary recall studies were conducted. The estimated dietary intake of Vitamins A and C using a 24-hour dietary recall method showed that all subjects had inadequate intake of these two vitamins. Other studies have reported inadequate dietary intake of vitamins as a potential reason for most disease conditions related to deficiencies in micronutrient [19]. Our field observations showed that the villages lacked Vitamin A, C, and D rich food sources. Dietary intake of Vitamin A and C were found to be below the recommended daily intake of between $500-850 \mu \mathrm{g} \mathrm{RE} / \mathrm{d}$ and $70 \mathrm{mg} / \mathrm{d}$ respectively. This intake pattern is, in part, attributable to the traditional Maasai diet which consists primarily of meat and dairy products, with little or no vegetable or fruit content [20]. The Maasai traditional food practices in part explain the results obtained in this study showing micronutrient deficiency in the study population. Additionally, the Maasai, on special occasions [21], consume blood from their livestock, which is a source of high protein, and is beneficial to the immune system. Consumption of vegetables is uncommon among Maasai due to the belief that green vegetables were meant for livestock feed [20] [22].

Global environmental changes marked with drought have pressured the way of life of the Maasai. Their eating habits and pattern have changed including a shift towards consuming cereal based meals due to the lack of enough milk and meat. The Maasai have also been migrating to other areas of Tanzania, which has led to exposure to and adoption of other people's food habits. As reported in the TDHS [14], micronutrient deficiencies are a result of inadequate intake of micronutrient-rich foods and inadequate utilization of available micronutrients due to dietary or physiological (i.e., infections) factors.

Prevalence of anaemia was $29 \%$ among the participating Maasai women of reproductive age; similar to findings of a prior study [23] which suggested that a maize and milk diet was insufficient to maintain a normal hemoglobin level. Manifestations of anaemia among Maasai women of reproductive age were considered in terms of low iron, folate, and/or Vitamin B12 intakes which were reflected in the 24-hour dietary recall. It is further noted that the bioavailability of these nutrients may be hindered by other food constituents. For example, total 
dietary intake of iron is not a valid indicator of iron deficiency unless it is accompanied with data on bio-availability [24]. In this study, we estimated dietary intake of iron, folate, and B12 as these are critical micronutrients whose deficiency may lead to anaemia. All these were found to be below the Recommended Nutrient Intake (RNI). In order to determine the exact levels of these nutrients, an analysis of serum ferritin levels, folate and B12 would be required to ascertain the exact cause of anaemia among the Maasai women.

In sub-Saharan African countries like Tanzania, Vitamin A deficiency is still an issue. Governments from local to regional levels need to support and encourage propagation of food systems that advocate the use of green leafy vegetables, natural greens, and fruits which are rich sources of micronutrients [25]. It is important that intensive and well structured programs are put in place to promote the consumption of locally available inexpensive fruits and vegetables [26]. Biodiversity of vegetables and leafy greens is an important factor in combating micronutrient malnutrition. It is well known that vegetables and fruits are good sources of micronutrients and are essential in combating micronutrient related malnutrition. Several studies [27]-[29] suggest that the consumption of leafy vegetables and fruits collected in the wild could be useful in combating micronutrient deficiencies especially in the tropics.

\section{Study Limitations}

This study had several limitations and opportunities. The study occurred in 3 select communities, so the potential exists to extend to other locales and to other potentially at risk groups of women. It was a cross-sectional study, so a replication or longitudinal study is warranted to ensure a follow up of subjects and their infants for micronutrient indicators and impacts. There is also an opportunity to assess pregnancy outcomes if this study was done longitudinally.

\section{Conclusions and Recommendations}

Results from this study revealed micronutrient deficiencies in Maasai women of reproductive age in the NCA. These deficiencies may contribute to a number of health outcomes in the NCA such as high levels of oral thrush and pregnancy difficulties. Nutrition education on the importance of eating micronutrient rich foods such as fruits and vegetables is highly recommended. Additionally, strategies such as government policies related to food fortification are required to improve women's micronutrient status. There is an imperative for more studies to further explore food habits, culture, and traditions associated with food intake among Maasai women of reproductive age.

\section{References}

[1] Jiang, T., Christian, P., Khatry, S.K., Wu, L. and West, K.P. (2005) Micronutrient Deficiencies in Early Pregnancy Are Common, Concurrent, and Vary by Season among Rural Nepali Pregnant Women. The Journal of Nutrition, 135 , 1106-1112.

[2] Bhaskaram, P. (2002) Micronutrient Malnutrition, Infection, and Immunity: An Overview. Nutrition Reviews, 60, S40-S45. http://dx.doi.org/10.1301/00296640260130722

[3] Martin, H.D., Petrucka, P. and Buza, J. (2014) Prevalence and Predictors of Oral Thrush among Maasai in Ngorongoro Conservation Area: A Preliminary Consideration. Open Journal of Medicine. (in press)

[4] Hodgson, D.L. (1999) Pastoralism, Patriarchy and History: Changing Gender Relations among Maasai in Tanganyika, 1890-1940. The Journal of African History, 40, 41-65. http://dx.doi.org/10.1017/S0021853798007397

[5] Hamza, O.J.M., Matee, M.I.N., Simon, E.N.M., et al. (2006) Oral Manifestations of HIV Infection in Children and Adults Receiving Highly Active Anti-Retroviral Therapy [HAART] in Dar es Salaam, Tanzania. BMC Oral Health, 6, 12. http://dx.doi.org/10.1186/1472-6831-6-12

[6] Dijkhuizen, M.A., Wieringa, F.T. and West, C.E. (2001) Concurrent Micronutrient Deficiencies in Lactating Mothers and Their Infants in Indonesia. The American Journal of Clinical Nutrition, 73, 786-791.

[7] Ramakrishnan, U. (2002) Prevalence of Micronutrient Malnutrition Worldwide. Nutrition Reviews, 60, S46-S52. http://dx.doi.org/10.1301/00296640260130731

[8] Allen, L.H. (2005) Multiple Micronutrients in Pregnancy and Lactation: An Overview. The American Journal of Clinical Nutrition, 81, 1206S-1212S.

[9] Darnton-Hill, I., Webb, P., Harvey, P.W., Hunt, J.M., Dalmiya, N., Chopra, M., et al. (2005) Micronutrient Deficiencies and Gender: Social and Economic Costs. The American Journal of Clinical Nutrition, 81, 1198S-1205S. 
[10] Golden, M.H. (1991) The Nature of Nutritional Deficiency in Relation to Growth Failure and Poverty. Acta Paediatrica, 80, 95-110. http://dx.doi.org/10.1111/j.1651-2227.1991.tb12012.x

[11] Prinzo, Z.W. and De Benoist, B. (2002) Meeting the Challenges of Micronutrient Deficiencies in Emergency-Affected Populations. Proceedings of the Nutrition Society, 61, 251-257. http://dx.doi.org/10.1079/PNS2002151

[12] National Bureau of Statistics (Tanzania) and ICF Macro (2012) Tanzania Population and Housing Census. Government of Tanzania, Dodoma.

[13] Coast, E. (2002) Maasai Socioeconomic Conditions: A Cross-Border Comparison. Human Ecology, 30, 79-105. http://dx.doi.org/10.1023/A:1014567029853

[14] Tanzania National Bureau of Statistics and ICF Macro (2011) 2010 Tanzania Demographic and Health Survey: Key Findings. NBS and ICF Macro, Calverton.

[15] Schleicher, R.L., Carroll, M.D., Ford, E.S. and Lacher, D.A. (2009) Serum Vitamin C and the Prevalence of Vitamin C Deficiency in the United States: 2003-2004 National Health and Nutrition Examination Survey (NHANES). The American Journal of Clinical Nutrition, 90, 1252-1263. http://dx.doi.org/10.3945/ajcn.2008.27016

[16] Woo, J., Lam, C.W., Leung, J., Lau, W.Y., Lau, E., Ling, X., et al. (2008) Very High Rates of Vitamin D Insufficiency in Women of Child-Bearing Age Living in Beijing and Hong Kong. British Journal of Nutrition, 99, 1330-1334. http://dx.doi.org/10.1017/S0007114507844382

[17] Li, W., Green, T.J., Innis, S.M., Barr, S.I., Whiting, S.J., Shand, A., et al. (2011) Suboptimal Vitamin D Levels in Pregnant Women despite Supplement Use. Canadian Journal of Public Health, 102, 308-312.

[18] Bischoff-Ferrari, H.A., Giovannucci, E., Willett, W.C., Dietrich, T. and Dawson-Hughes, B. (2006) Estimation of Optimal Serum Concentrations of 25-Hydroxyvitamin D for Multiple Health Outcomes. The American Journal of Clinical Nutrition, 84, 18-28.

[19] Tontisirin, K., Nantel, G. and Bhattacharjee, L. (2002) Food-Based Strategies to Meet the Challenges of Micronutrient Malnutrition in the Developing World. Proceedings of the Nutrition Society, 61, 243-250. http://dx.doi.org/10.1079/PNS2002155

[20] Mpoke, S., Johnson, K.E. and Anderson, N.L.R. (1993) Baseline Survey of Pregnancy Practices among Kenyan Maasai. Western Journal of Nursing Research, 15, 298-313. http://dx.doi.org/10.1177/019394599301500303

[21] Hetfield, J. (2005) The Maasai of East Africa. Rosen Classroom, New York.

[22] Nestel, P. and Geissler, C. (1986) Potential Deficiencies of a Pastoral Diet: A Case Study of the Maasai. Ecology of Food and Nutrition, 19, 1-10. http://dx.doi.org/10.1080/03670244.1986.9990941

[23] Brady, R., Suksiri, S., Tan, S., Dodds, J. and Aine, D. (2008) Current Health and Environmental Status of the Maasai People in Sub-Saharan Africa. Honors Undergraduate Research Journal, 1, 17-32.

[24] Seshadri, S. (2001) Prevalence of Micronutrient Deficiency Particularly of Iron, Zinc and Folic Acid in Pregnant Women in South East Asia. British Journal of Nutrition, 85, S87-S92. http://dx.doi.org/10.1079/BJN2000299

[25] Latham, M. (2010) The Great Vitamin A Fiasco. World Nutrition, 1, 12-45.

[26] Heywood, V.H. (2011) Ethnopharmacology, Food Production, Nutrition and Biodiversity Conservation: Towards a Sustainable Future for Indigenous Peoples. Journal of Ethnopharmacology, 137, 1-15. http://dx.doi.org/10.1016/j.jep.2011.05.027

[27] Uusiku, N.P., Oelofse, A., Duodu, K.G., Bester, M.J. and Faber, M. (2010) Nutritional Value of Leafy Vegetables of Sub-Saharan Africa and Their Potential Contribution to Human Health: A Review. Journal of Food Composition and Analysis, 23, 499-509. http://dx.doi.org/10.1016/j.jfca.2010.05.002

[28] Price, L.L. and Ogle, B.M. (2008) Gathered Indigenous Vegetables in Mainland Southeast Asia: A Gender Asset. In: Resurreccion, B.P. and Elmhirst, R., Eds., Gender and Natural Resource Management: Livelihoods, Mobility and Interventions, Earthscan Publications Ltd., London, 213-242.

[29] Pretty, J. (2007) Earth Only Endures: On Reconnecting with Nature and Our Place in It. Earthscan Publications Ltd., London. 